\title{
Kireçtaşı Mermerlerinin Fiziko-mekanik Özellikleri ile P Dalga Hızı Arasındaki İlişkinin İncelenmesi
}

\author{
Özen KILIÇ ${ }^{* 1}$, Esma KAHRAMAN ${ }^{1}$, Ahmet Mahmut KILIÇ ${ }^{1}$ \\ ${ }^{1}$ Çukurova Üniversitesi, Mühendislik Mimarlık Fakültesi, Maden Mühendisliği Bölümü, Adana
}

Geliş tarihi: 15.02 .2018

Kabul tarihi: 29.06 .2018

$\ddot{\mathbf{O} z}$

Ultrasonik teknikler madencilik alanında ve jeoteknik uygulamalarda yaygın olarak kullanılmaktadır. Kayaç numuneleri üzerine kolay uygulanabilmesi, ekonomikliği ve basit bir şekilde numune hazırlanması vb. gibi olumlu özellikleri yöntemi çekici hale getirmektedir. Doğal taşların ultrasonik iletkenliğini etkileyen pek çok faktör mevcuttur. Bu çalışma kapsamında; farklı bölgelere ait kireçtaşı mermerlerinin tek eksenli basınç dayanımı, su emme oranı, Shore sertliği ve özgül ağırlıkları laboratuvar ortamında belirlenmiş ve $\mathrm{P}$ dalga hızı ile basit ve çoklu regresyon analizleri yapılarak ampirik formüller elde edilmiştir. Regresyon analizi, P dalga hızı değerlerinin tek eksenli basınç dayanımı, su emme oranı, Shore sertliği ve özgül ağırlık değerleri ile kuvvetli bir ilişki olduğunu göstermektedir.

Anahtar Kelimeler: P dalga hızı, Kireçtaşı mermerleri, Fiziko-mekanik özellikler

\section{Examination of the Relationship between P Wave Velocity and Physico-mechanical Properties of Limestone Marbles}

\begin{abstract}
Ultrasonic techniques are widely used in mining and geotechnical applications. The positive features such as easy application on rock samples, economical and easy sample preparation make the method attractive. There are many factors that affect the ultrasonic conductivity of natural stones. In this study, uniaxial compressive strength, water absorption rate, Shore hardness and specific gravity of limestone marbles belonging to different regions were determined in the laboratory. Empirical formulas were obtained by performing simple and multiple regression analysis with $\mathrm{P}$ wave velocities measured from marble blocks. Regression analysis showed that $\mathrm{P}$ wave velocity values were strongly correlated with uniaxial compressive strength, water absorption rate, Shore hardness and specific gravity values.
\end{abstract}

Keywords: P wave velocity, Limestone marble, Physico-mechanical properties

*Sorumlu yazar (Corresponding author): Özen KILIÇ, zenkilic@cu.edu.tr 


\section{GíRiş}

Sismik teknikler, tahribatsız ve kolay uygulanabilir olmasından dolayı madencilik, inşaat ve jeofizik çalışmalarda sıklıkla kullanılmaktadır. Madencilik alanında özellikle kayaçların bazı mekanik ve fiziksel özelliklerinin tayininde uygulanmaktadır.

Kayaçlarda P dalgası hızını etkileyen başlıca faktörler litoloji, doku, yoğunluk, gözeneklilik, anizotropi, tane boyutu ve şekli, su teması, gerilme, sıcaklık, hava koşulları, alterasyon zonları, gözenekler ve mikro çatlaklar ve yataklanma düzlemleridir [1].

Ultra sonik hız deneyi ile kayaçların P (boyuna dalga boyu) ve S (enine dalga boyu) dalga hizları belirlenerek, dinamik Elastisite modülü, rijitlik modülü, bulk modülü ve poisson oranı da ilgili eşitlikler yardımıyla hesaplanabilmektedir [2].

Bu çalışmada; farklı bölgelerden getirilen kireçtaşı mermerlerinin su emme, Shore sertliği, tek eksenli basınç dayanımı ve özgül ağırlık değerleri laboratuvar ortamında belirlenmiş ve bu değerlerin $\mathrm{P}$ dalga hızı ile olan ilişkisi incelenmiştir. Çalışma sonucunda yapılan basit ve çoklu regresyon analizi ile P dalga hızının tahmini için ampirik formüller üretilmiştir.

\section{2. ÖNCEKİ ÇALIŞMALAR}

Altındağ [1] yaptı̆̆ı çalışmada P dalga hızı ile tek eksenli basınç dayanımı, birim hacim ağırlık, elastisite modülü, gözeneklilik ve nokta yük indeksi arasındaki ilişkiyi incelemiştir.

Kılıç ve Teymen [3] yaptıkları çalışma ile kayaçların fiziksel ve mekanik özellikleri arasındaki ilişkiyi incelemişler ve $\mathrm{P}$ dalga hızı ile tek eksenli basınç dayanımı arasında yüksek bir ilişkinin varlığını tespit etmişlerdir.

Yaşar ve Erdoğan [4] özellikle doğal yap1 ve kaplama taşı olarak kullanılabilecek kayaların $\mathrm{P}$ dalga hızı ile fiziko-mekanik özelliklerinden tek eksenli basınç dayanımı, Elastisite modülü, ve birim hacim ağırlığı arasındaki ilişkilerin varlığını istatistiksel analizlerle ortaya çıkarılmışlardır.

Babacan ve arkadaşları [5] Doğu Karadeniz Bölgesi'nde yer alan Berdiga Formasyonu'na ait bej renkli kireçtaşlarının, $P$ dalga hızlarını laboratuvarda belirlenmişlerdir. $\mathrm{Bu}$ hızlar yardımıyla kayaçlarının kalitesi hakkında bilgi veren dinamik-elastik parametreleri hesaplamışlardır.

P dalga hızının kayaçların fiziksel ve mekanik özelliklerinin ilişkilendirilmesinin dışında farklı alanlarda da kullanıldığını gösteren araştırmalar bulunmaktadır. Young ve arkadaşları [6] yaptıkları çalışmada kazı çalışmalarında uygulanan patlatmalarda patlatma veriminde etkili olan parçalanmayı P dalgası ile ilişkilendirmiştir. Kayaçların ayrışma dereceleri ve ayrışma derinliğinin tahmininde de $\mathrm{P}$ dalga hızı kullanılmıştır $[7,9]$.

Bazı çalışmalarda; kaya mekaniğinde en önemli kavramlar arasında olan kaya kütlelerindeki gerilme ve deformasyonlarin tespitinde $\mathrm{P}$ dalgasından faydalanılmıştır $[10,11]$.

Yapı taşlarında plaka verimi değerlendirmede de $\mathrm{P}$ dalga hızı kullanılmıştır. Ultrasonik ölçümlerden elde ettikleri verileri değerlendirerek plaka veriminin tahmin edilebileceğini belirlemişlerdir [12].

\section{MATERYAL VE METOT}

\subsection{Materyal}

$\mathrm{Bu}$ çalışma kapsamında kullanılan kireçtaşı mermerleri Çukurova Bölgesinde üretim yapan farklı mermer ocaklarından temin edilmiştir.

Numuneler $10 \times 10 \times 10 \mathrm{~cm}$ ve $4 \times 4 \times 4 \quad \mathrm{~cm}$ 'lik boyutlarda deney standartlarına uygun olarak hazırlanmıştır (Şekil 1). Bu amaç için 47 adet örnek hazırlanmıştır ve örnekler üzerinde ilgili testler yapılmıştır. 


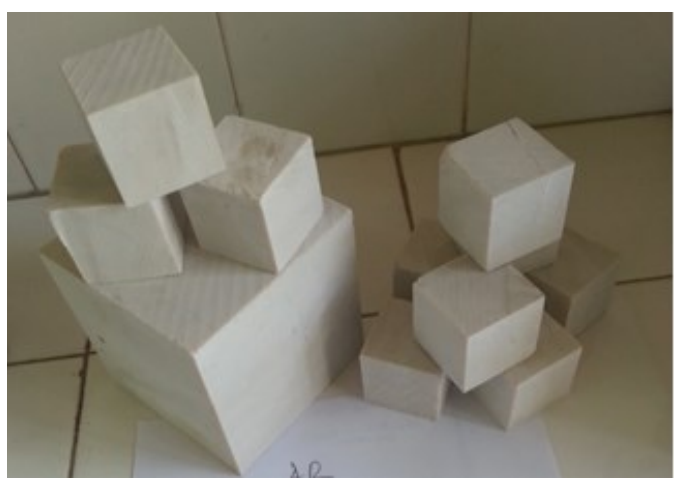

Şekil 1. Boyutlandırılmış kireçtaşı mermeri örneği

\subsection{Metot}

Günümüzde doğal taşların, yapıların iç ve diş döşemesinde kullanılabilmesine karar verebilmek için bir takım fiziko-mekanik parametrelerin belirlenmesi gerekir. Kireçtaşı mermer numuneleri üzerinde gerçekleştirilen fiziksel ve mekanik deneyler TS 699/T1 [13], 'Doğal yapı taşları inceleme ve laboratuvar deney yöntemleri' standardına göre belirlenmiştir.

Deney sonuçları kullanılarak Minitab 18 paket programı ile basit ve çoklu regresyon analizi yapılmıştır.

P Dalga Hızı Tavini: P dalga hızı jeofizik çalışma alanlarında ve kayaçların dinamik özelliklerinin laboratuarlardaki tespitinde kullanılır. Deney silindirik veya kübik olarak hazırlanan deney numuneleri üzerinde gerçekleştirilmektedir. Ultrasonik test ölçümleri Proceq Inc. şirketi tarafından üretilen cihaz kullanılarak yapılmıştır (Şekil 2).

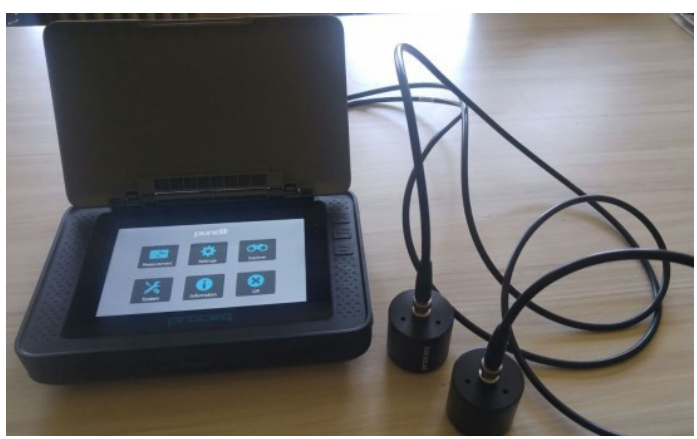

Şekil 2. Ultrasonik test cihazı
$\mathrm{P}$ dalga hızına göre kayaçların sınıflandırılması Çizelge 1'de verilmiştir.

Çizelge 1. Dalga hız sınıflaması [14]

\begin{tabular}{|c|c|c|}
\hline Sinıf & Dalga Hiz $(\mathrm{km} / \mathrm{sn})$ & Tanımlama \\
\hline 1 & $<2,5$ & Çok düşük hız \\
\hline 2 & $2,5-3,5$ & Düşük hız \\
\hline 3 & $3,5-4$ & Orta hız \\
\hline 4 & $4-5$ & Yüksek hız \\
\hline 5 & $>5$ & Çok yüksek hız \\
\hline
\end{tabular}

Shore Sertliği: Doğal taşların fiziksel özelliklerinden biri olan sertlik, temel olarak kayacın mineralojisinden, bağlayıcı madde özelliklerinden, matrix tipinden ve elastisitesinden etkilenmektedir [2]. Shore sertliği, tane boyutu 0,2 mm'den büyük kayaçlar için sert minerallerin yüzdesinin hızlı ölçümünü ortaya koymak için kullanılabilmekte ve kayaç mineralojisi ile doğrudan ilişkisi bulunmaktadır [15]. Shore sertliği ölçümünde araştırmacılar tarafından farklı numune boyutları önerilmektedir [16-19]. Ölçümlerde Shore Scelerescope'u kullanılmaktadır. Numuneler üzerinde ISRM [17]'de belirtilen ölçüm prensipleri uygulanmıştır.

Özgül A yoğunluğunun ölçümü ile ilgilidir. Çalışma sahasının değişik yerlerinden alınan temsili numuneler, 0,2 mm'lik eleklerden geçecek şekilde öğütülmüş ve sabit ağırlığa gelene kadar $105{ }^{\circ} \mathrm{C}$ sicaklıkta etüvde kurutularak piknometre ile özgül ağırlık değerleri tespit edilmiştir [2].

Su Emme Oranı: Ağırlıkça su emme deneyi kayaç örneklerinin ağırlıklarına oranla, boşluklarının alabileceği su miktarının saptaması amacıyla yapılmaktadır [20].

Tek Eksenli Basınç Dayanımı: Basınç dayanımı, belirli bir yüke karşı kayaçların kırılmadan önceki maksimum dayanabilme yeteneği olarak tanımlanmaktadır. Deney numunesi düzgün geometrik şekilli küp, prizma veya karot şeklinde olabilmektedir. Karot numunelerinde boy/çap oranının 2-2,5 arası olmalıdır. ELE marka elektronik hidrolik pres numune üzerine düşey olarak yük uygulamakta ve uygulanan yükü ölçerek göstermektedir. 


\section{ARAŞTIRMA BULGULARI}

Çukurova Bölgesi'nden elde edilmiş 47 farklı numune üzerinde $\mathrm{P}$ dalga hızı, Shore sertliği, özgül ağırlık, su emme oranı, tek eksenli basınç dayanımı deneyleri uygulanmış ve deney sonuçları kullanılarak değişkenler arasında ilişki kurulmuştur. İstatistiksel analizler Minitab 18 programı kullanılarak yapılmıştır.

\subsection{Basit Regresyon Analizi Sonuçları}

Her bir bağımsız değişken için basit regresyon analizleri yapılmıştır. Bağımsız değişken tarafından açıklanan bağımlı değişkendeki değişim oranı $\mathrm{R}^{2}$ kullanılarak değerlendirilmiștir. 1'e yakın olan $\mathrm{R}^{2}$ değeri bağımlı değişkendeki değişkenliğin çoğunu regresyon modeli tarafindan açıklandığını gösterir.

İlk olarak, Çukurova bölgesi kireçtaş1 mermerlerinin P dalga hızı değerleri ile Shore sertlik değerleri arasındaki ilişki değerlendirilmiştir (Şekil 3). P dalga hızı ile Shore sertliği arasındaki ilişkinin kuvvetindeki değişimi açıklama oranı yani $\mathrm{R}^{2}$ değeri 0,913 olarak bulunmuştur. Hata kareleri ortalaması ise 0,028 olarak belirlenmiştir. Ayrıca P dalgasının tahmini için oluşturulan eşitlik grafik üzerinde verilmiştir.

P dalgası ile özgül ağırlık verileri incelendiğinde iki değişken arasındaki ilişkinin kuvvetindeki değişimi açıklama oranı yani $\mathrm{R}^{2}$ değeri 0,882 olarak bulunmuştur. $\mathrm{Bu}$ oranı destekleyen eşitlik grafik üzerinde belirtilmiştir (Şekil 4). Hata kareleri ortalaması ise 0,038 olarak belirlenmiştir.

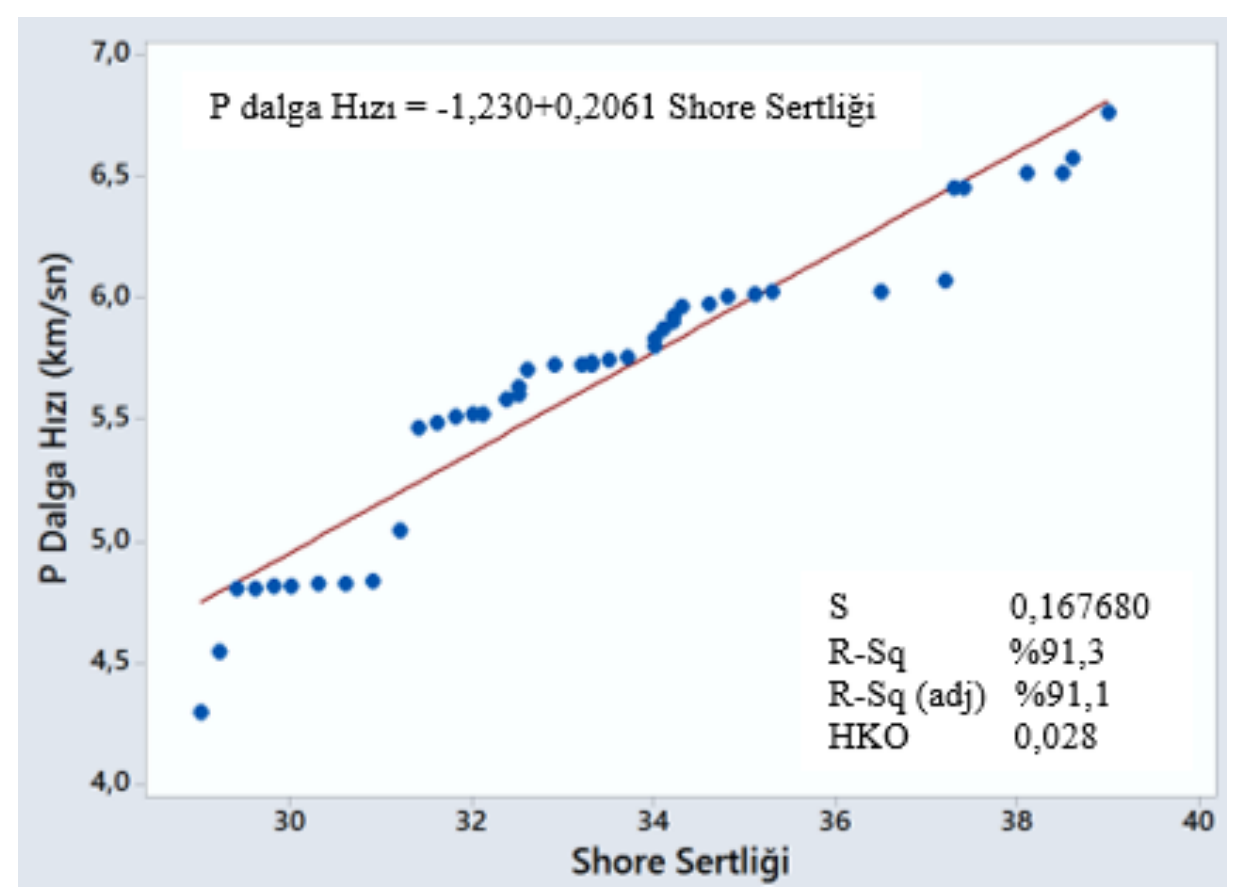

Şekil 3. P dalga hızı ile Shore sertliği arasındaki ilişki

Çukurova bölgesi kireçtaşı mermerlerinin P dalga hızı değerleri ile su emme oranı arasındaki ilişki incelendiğinde iki değişken arasındaki ilişkinin kuvvetindeki değişimi açıklama oranı yani ilişkinin şiddetinin göstergesi olan $\mathrm{R}^{2}$ değeri 0,836 olarak bulunmuştur. $\mathrm{Bu}$ sonuç bize, $\mathrm{P}$ dalga hızı değerinin \%83,6'sının su emme oranı ile açıklanabildiğini göstermektedir. Hata kareleri ortalaması ise 0,053 olarak değerlendirilmiştir (Şekil 5). 


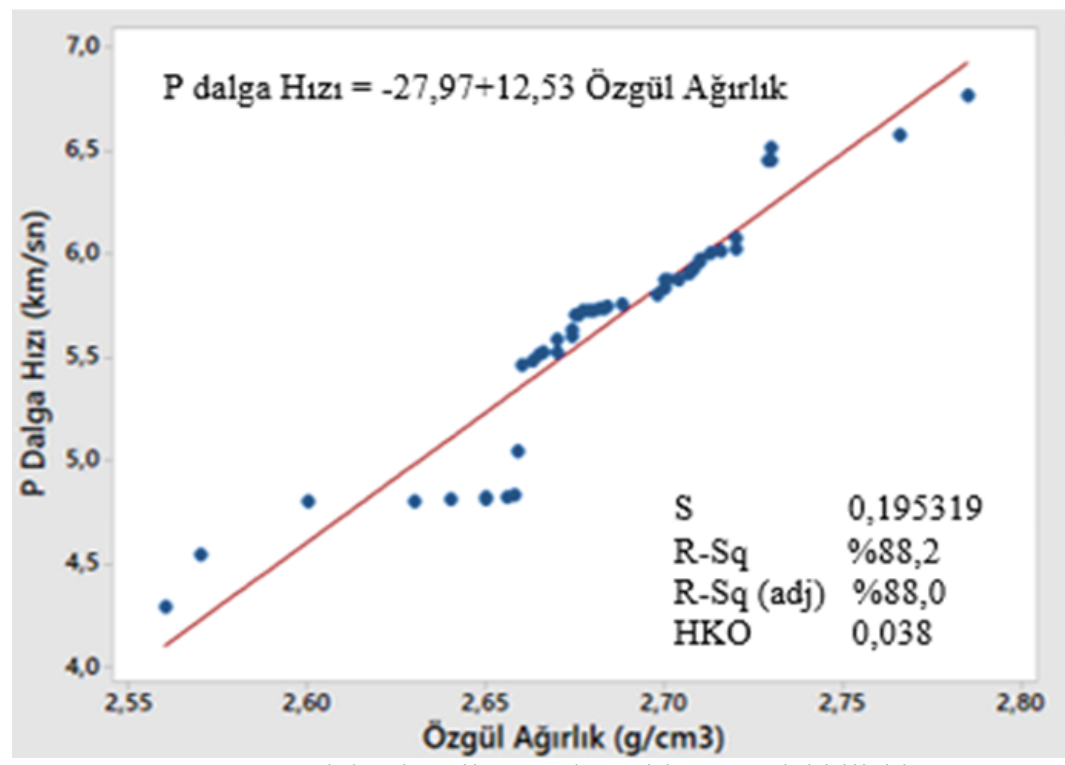

Şekil 4. P dalga hızı ile özgül ağırlık arasındaki ilişki

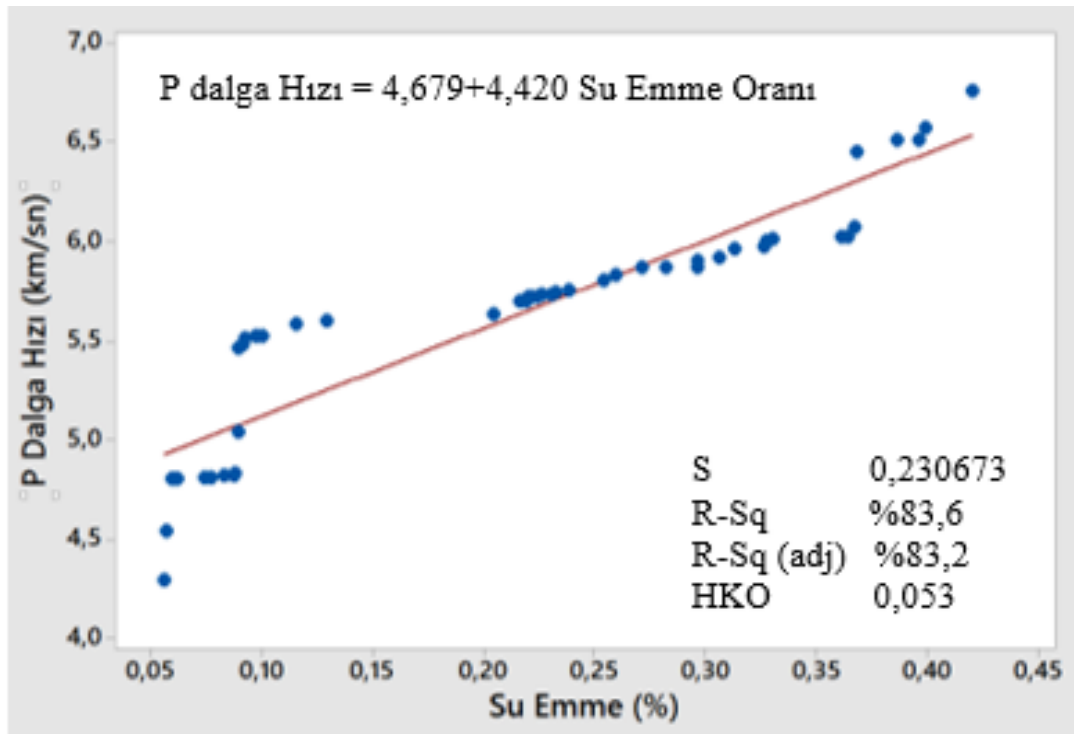

Şekil 5. P dalga hızı ile su emme oranı arasındaki ilişki

P dalga hızı ile tek eksenli basınç dayanımı (TEBD) arasındaki ilişki incelendiğinde iki değişken arasındaki ilişkinin kuvvetindeki değişimi açıklama oranı yani $\mathrm{R}^{2}=0,877$ olarak bulunmuştur. Hata kareleri ortalaması ise 0,040 olarak belirlenmiştir. Ayrıca P dalgasının tahmini için tek eksenli basınç dayanımı ile oluşturulan eşitlikte grafik üzerinde verilmiştir (Şekil 6).

\section{2. Çoklu Regresyon Analizi Sonuçları}

P dalga hızının tüm bağımsız değişkenlerle olan ilişkisini belirlemek amacıyla çoklu regresyon analizi yapılmıştır. Analiz sonucunda $\mathrm{P}$ dalga hızının diğer dört değişken ile (Shore sertliği, özgül ağırlık, su emme ve tek eksenli basınç dayanımı) arasındaki ilişkinin kuvvetindeki 
değişimi açıklama oranı $\mathrm{R}^{2}$ değeri 0,932 olarak belirlenmiş, hata kareleri ortalaması ise 0,021 bulunmuştur (Şekil 5). P dalgasının tahmini için belirlenen eşitlik grafik üzerinde gösterilmişstir.
Eşitlik yardımıyla tahmin edilen $\mathrm{P}$ dalga hızı ve ölçülen $\mathrm{P}$ dalga hızı arasındaki farklar belirlenmiştir (Çizelge 2).

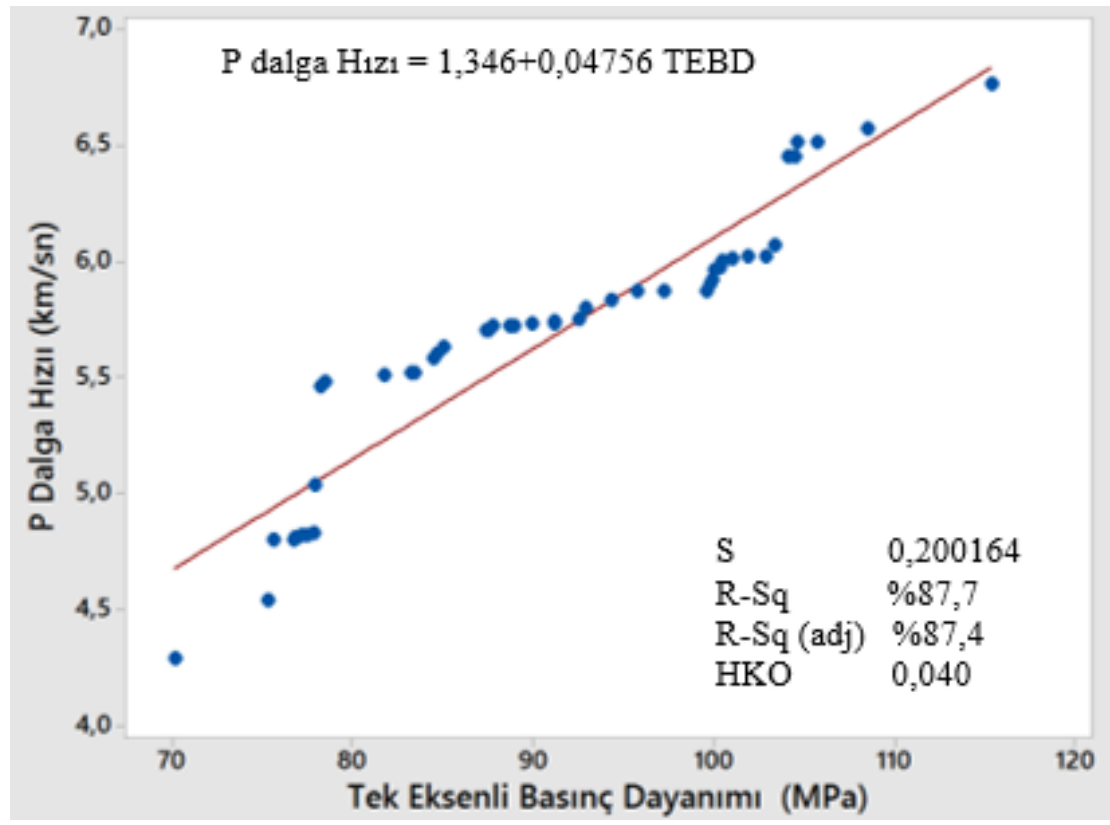

Şekil 6. P dalga hızı ile tek eksenli basınç dayanımı arasındaki ilişki

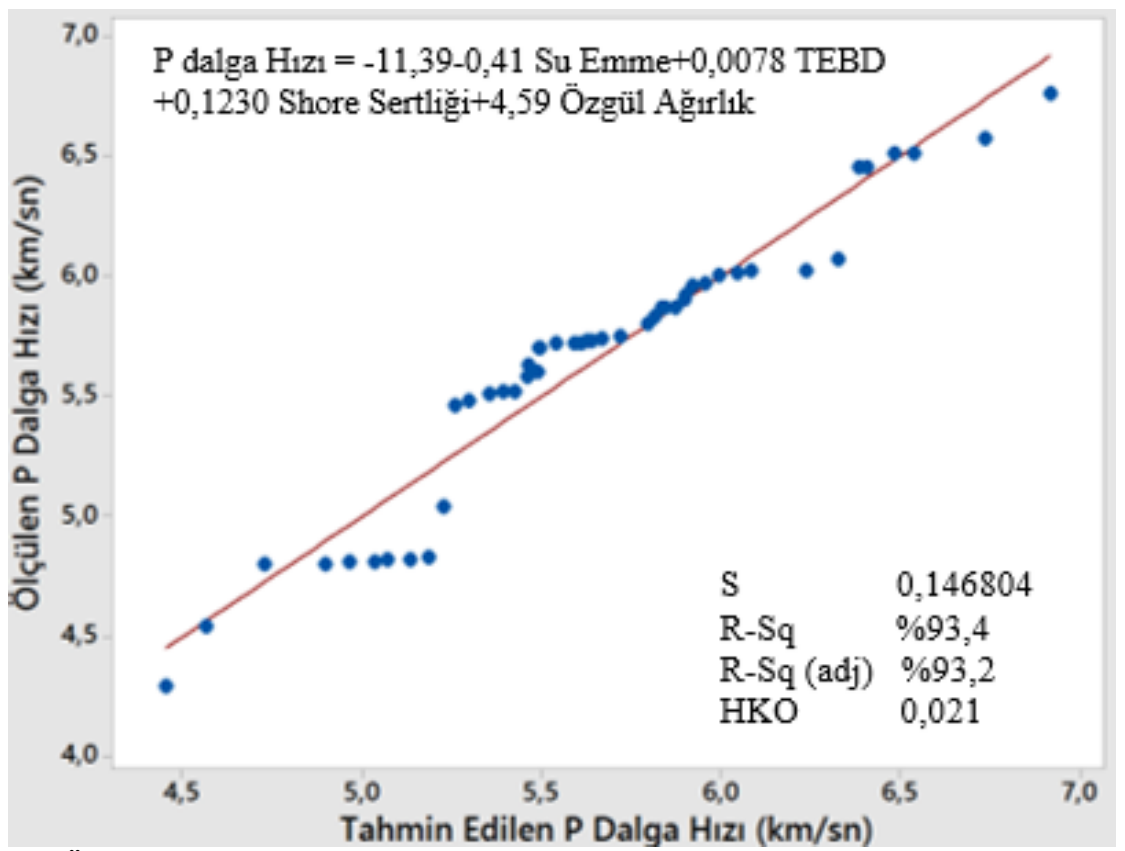

Şekil 5. Ölçülen P dalgası değerleri ile tahmin edilen $P$ dalgası değerleri arasındaki ilişki 
Çizelge 2. Ölçülen ve tahmin edilen P dalga hızı değerleri ve arasındaki farklar

\begin{tabular}{|c|c|c|c|}
\hline No & $\begin{array}{c}\text { P dalga hızı } \\
\text { (km/sn) }\end{array}$ & $\begin{array}{c}\text { Tahmin edilen P } \\
\text { dalga hizı (km/sn) }\end{array}$ & Hata \\
\hline 1 & 6,76 & 6,91 & 0,156 \\
\hline 2 & 6,57 & 6,73 & 0,165 \\
\hline 3 & 6,51 & 6,53 & 0,027 \\
\hline 4 & 6,51 & 6,48 & 0,026 \\
\hline 5 & 6,45 & 6,40 & 0,045 \\
\hline 6 & 6,45 & 6,38 & 0,065 \\
\hline 7 & 6,07 & 6,32 & 0,255 \\
\hline 8 & 6,02 & 6,23 & 0,216 \\
\hline 9 & 6,02 & 6,08 & 0,063 \\
\hline 10 & 6,01 & 6,04 & 0,036 \\
\hline 11 & 6,00 & 5,99 & 0,007 \\
\hline 12 & 5,97 & 5,95 & 0,016 \\
\hline 13 & 5,96 & 5,91 & 0,040 \\
\hline 14 & 5,92 & 5,89 & 0,020 \\
\hline 15 & 5,90 & 5,89 & 0,001 \\
\hline 16 & 5,87 & 5,87 & 0,000 \\
\hline 17 & 5,87 & 5,84 & 0,025 \\
\hline 18 & 5,87 & 5,83 & 0,036 \\
\hline 19 & 5,83 & 5,81 & 0,015 \\
\hline 20 & 5,80 & 5,79 & 0,003 \\
\hline 21 & 5,75 & 5,71 & 0,032 \\
\hline 22 & 5,74 & 5,66 & 0,073 \\
\hline 23 & 5,73 & 5,63 & 0,092 \\
\hline 24 & 5,73 & 5,62 & 0,104 \\
\hline 25 & 5,72 & 5,60 & 0,110 \\
\hline 26 & 5,72 & 5,59 & 0,128 \\
\hline 27 & 5,72 & 5,53 & 0,181 \\
\hline 28 & 5,70 & 5,49 & 0,204 \\
\hline 29 & 5,70 & 5,49 & 0,204 \\
\hline 30 & 5,63 & 5,46 & 0,168 \\
\hline 31 & 5,60 & 5,48 & 0,110 \\
\hline 32 & 5,58 & 5,45 & 0,122 \\
\hline 33 & 5,52 & 5,42 & 0,096 \\
\hline 34 & 5,52 & 5,39 & 0,126 \\
\hline 35 & 5,51 & 5,35 & 0,155 \\
\hline 36 & 5,48 & 5,29 & 0,184 \\
\hline 37 & 5,46 & 5,25 & 0,203 \\
\hline 38 & 5,04 & 5,22 & 0,184 \\
\hline 39 & 4,83 & 5,18 & 0,352 \\
\hline 40 & 4,82 & 5,13 & 0,314 \\
\hline 41 & 4,82 & 5,06 & 0,249 \\
\hline 42 & 4,81 & 5,03 & 0,222 \\
\hline 43 & 4,81 & 4,96 & 0,152 \\
\hline 44 & 4,80 & 4,89 & 0,096 \\
\hline 45 & 4,80 & 46,073 \\
\hline 46 & 4,54 & & 0,162 \\
\hline 47 & 4,29 & & \\
\hline & & & \\
\hline
\end{tabular}

\section{SONUÇLAR}

Bu çalışmada, Çukurova Bölgesi'nden alınmış 47 farklı kireçtaşı mermeri üzerinde Shore sertliği, özgül ağırlık, su emme oranı ve tek eksenli basınç dayanımı ve P dalgası deneyleri yapılmıştır. Elde edilen deney sonuçları ile $\mathrm{P}$ dalgası tahmini için basit ve çoklu regresyon yapılmıştır. Yapılan regresyon modelleri ile bağımlı değişken ile bağımsız değişkenler arasında güçlü bir ilişki olduğu tespit edilmiştir. Ayrıca $\mathrm{P}$ dalga hızı tahmini için ampirik formüller üretilmiștir. Yapılan analizler ile elde edilen grafiklere göre $\mathrm{P}$ dalga hızı aşağıda verilen doğruluk oranları ile hesaplatılabilmektedir.

- Shore sertlik oranından P dalga hızı \%91,3

- Özgül ağırlık değerinden P dalga hızı \%88,2

- Su emme oranında P dalga hizı \%83,6

- Tek eksenli basınç dayanımı değerinden P dalga hız1 \%87,7'dir.

Ayrıca çoklu regresyon analizi incelendiğinde Çukurova bölgesi kireçtaşı mermerlerinde Shore sertlik oranı, özgül ağırlık değeri, su emme oranı ve tek eksenli basınç dayanımı değeri kullanılarak P dalga hızı \%93,2 doğruluk oranı ile hesaplatılabilecektir. Sonuç olarak; P dalga hızının doğruluk oranının yüksek olması, araştırılan parametreler arasında kuvvetli bir ilişkinin olduğunu göstermektedir.

\section{TEŞEKKÜR}

$\mathrm{Bu}$ çalışma, FBA-2017-8517 nolu proje kapsamında yapılmış olup Çukurova Üniversitesi Rektörlüğü BAP Koordinasyon Birimi tarafindan desteklenmiştir.

\section{KAYNAKLAR}

1. Altındağ, R., 2012. Correlation between PWave Velocity and Some Mechanical Properties for Sedimentary, Rocks, Journal of the Southern African Institute of Mining and Metallurgy, 112(3), 229-237.

2. Gündüz, L., Ertürk, A., Tosun, Y., Sarıı̧ık, A., 1996. Mermer Teknolojisi, Tura Ofset, 
Süleyman Demirel Üniversitesi Mühendislik Fakültesi, Isparta.

3. Kılıç, A., Teymen, A., 2008. Determination of Mechanical Properties of Rocks using Simple Methods, Bulletin of Engineering Geology and the Environment, 67(2), 237.

4. Yaşar, E., Erdoğan, Y., 2003. Yap1-Kaplama Kayalarının P Dalga Hızı ile Fiziko-Mekanik Özellikleri Arasındaki İlişkilerin İstatistiksel Analizi, Türkiye IV. Mermer Sempozyumu (Mersem'2003) Bildiriler Kitab1, Ankara, 353-362.

5. Babacan, A. E., Ersoy, H., Gelişli, K., 2012. Kayaçların Fiziksel, Mekanik ve Elastik Özelliklerinin Ultrasonik Hiz Tekniği ve Zaman-Frekans Analiziyle Belirlenmesi: Bej Kireçtaşları (KD Türkiye) Üzerine Örnek Bir Çalışma, Jeoloji Mühendisliği Dergisi, Teknik Not, 36(1), 2012.

6. Young, R.P., Hill, T.T., Bryan I.R. Middleton, R., 1985. Seismic Spectroscopy in Fracture Characterization Quart, J. Eng. Geol., 18, 459-479.

7. Karpuz, C., Pasamehmetoglu, A.G., 1997. Field Characterization of Weathered Ankara Andesites, Eng. Geol., 17.

8. Christaras, B., Mariolakos, I., Foundoulis, J., Athanasias, S., Dimitriou, A., 1997. Geotechnical Input for the Protection of Some Macedonian Tombs in Northern Greece, Proceedings of the $6^{\text {th }}$ International Symposium Conservation of Monuments in the Mediterranean Basin, Rhodes, 125-132.

9. Christaras, B., 2003. P-wave Velocity and Quality of Building Materials, Proceedings of the International Symposium Industrial Minerals and Building Stones, Istanbul,

10. Onodera, T.F., 1963. Dynamic Investigation of Foundation Rocks, in Proceedings of the Fifth US Symposium on Rock Mechanics, 517-33, Pergamon Press, New York.

11. Gladwin, M.T., 1982. Ultrasonic Stres Monitonng in Underground Mining, Int J Rock Mech Sci., 19, 221-8.

12. Sakcalı, A., Yavuz, H., 2015. Mermer, Bej ve Traverten Bloklarında Plaka Veriminin Ultrasonik Ölçümlerle Analizi, Türkiye 24. Uluslararası Madencilik Kongresi ve Sergisi, Antalya.
13. TS 699/T1, 2016. Doğal Yapı Taşları-İnceleme ve Laboratuvar Deney Yöntemleri, Ankara.

14. Anon., 1979. Classification of Rocks and Soils for Engineering Geological Mapping Part IRock and Soil Materials Bull Int Ass Geo, I9, 64-371.

15. McFeat-Smith, I., 1977. Rock Property Testing for the Assessment of Tunnelling Machine Performance, Tunnels and Tunnelling, 29-33.

16. Misra, B., 1972: Correlation of Rock Properties with Machine Performance, Ph.D. Thesis, University of Leeds.

17. ISRM, 1981. Rock Characterisation Testing and Monitoring. In: Brown, E. T. (ed.) Pergamon Press, Oxford.

18. Rabia, H., Brook, N., 1979. The Shore Hardness of Rock, Technical Note, Int. J. Rock Mech. Min. Geomech. Abstr., 16, 335-336.

19. Altındağ, R., 2002. Effects of Specimen Volume and Temperature on Measurements of Shore Hardness, Technical Note, Rock Mech. Rock Engng., 35(2), 109-113.

20. Teymen, A., 2005. Bazı Kayaçların Petrografik, Fiziksel ve Mekanik Özelliklerinin İncelenmesi, Yüksek Lisans Tezi, Çukurova Üniversitesi, Adana, 136. 